\title{
Gelişimsel kalça displazisinde ultrasonografik inceleme
}

\section{Ultrasonographic evaluation in developmental dysplasia of the hip}

\author{
Mehmet Müfit Orak , Tolga Onay ${ }^{2}$ \\ ${ }^{1}$ Fatih Sultan Mehmet Eğitim ve Araştırma Hastanesi, Ortopedi ve Travmatoloji Kliniği \\ ${ }^{2}$ Marmara Üniversitesi Pendik Eğitim ve Araştırma Hastanesi, Ortopedi ve Travmatoloji Kliniği
}

\begin{abstract}
Gelişimsel kalça displazisi (GKD), çocukluk çağının en sık rastlanan kas-iskelet sistemi anomalisidir. Tedavisiz bırakıldığında kalıcı sakatlık ve deformitelere yol açar. Doğumda basit bir asetabular yetmezlik iken, patoloji ilerleyerek kalça luksasyonuna neden olabilmektedir. Fizik muayene bulgusu tespit edilemeyen erken aşamada tanının konması tedavinin başarısını belirleyen en önemli etmendir. Barlow ve Ortolani testlerinin özgünlüğü yüksek olmak birlikte, duyarlılığı düşüktür. Yenidoğan döneminde kalçanın kemik anatomisi yeterince gelişmemiştir. Bundan ötürü konvansiyonel radyolojik görüntüleme yetersiz kalmaktadır. Graf tarafından geliştirilen kalça ultrasonografi tekniği ile kalça kıkırdak ve yumuşak doku anatomisi direkt olarak görüntülenmektedir. Bu metot, son $30 \mathrm{yll}$ içerisinde geniş kabul görmüş olup GKD erken tanısında en önemli yöntem haline gelmiştir. Kalça ultrasonografisinin yaygın kullanımıyla birlikte, cerrahi prosedürlere olan gereksinim belirgin ölçüde azalmıştır. Kalça ultrasonografisinin doğru uygulanması ve yorumlanması ile geç dönem GKD komplikasyonları azaltılabilir.
\end{abstract}

Anahtar sözcükler: kalça displazisi, gelişimsel; ultrasonografi; Graf metodu

\section{GiRiş}

Gelişimsel kalça displazisi (GKD), çocukluk çağının en sık görülen kas iskelet sistemi anomalisidir; ${ }^{[1]}$ eğer saptanamaz ve tedavisiz bırakılırsa, hastada kalıcı deformitelere ve artroza yol açabilir; ayrıca, iş gücü kaybına ve hastanın yaşam kalitesinin düşmesine neden olur. ${ }^{[2]}$ Kalça osteoartritleri \%5-10 oranında GKD nedeniyledir. ${ }^{[3]}$ Çimentosuz total kalça protezlerinin $\% 9,1$ 'inin, çimentolu total kalça protezlerinin \%5,2'sinin kalça displazisi veya çıkığı nedeniyle yapıldığı gösterilmiş̧ir. ${ }^{[4]}$

\begin{abstract}
Developmental dysplasia of the hip (DDH) is the most common skeletal dysplasia of childhood. If left untreated, it can lead to permanent deformities and disabilities. While it was a simple acetabular deficiency at birth, the pathology may progress and lead to hip dislocation. At stages in which any physical examination finding cannot be assigned, early diagnosis is the most important factor which determined the success of the treatment. Barlow and Ortolani maneuvers have high specificity, while their sensitivity is low. The development of osseous anatomy of the hip is not mature enough in newborn period. Therefore conventional radiological imaging proves insufficient. The cartilagenous and soft tissue anatomy of the hip can be visualized directly with ultrasonographic hip imaging technique, which was developed by Graf. This method has gained widespread acceptance in the last 30 years and has become the most important diagnostic tool for early diagnosis of DDH. The need for surgical procedures decreased significantly with the widespread use of hip ultrasonography. Late term DDH complications may be reduced by the right application and interpretation of the hip ultrasonography.
\end{abstract}

Key words: dysplasia of hip, developmental; ultrasonography; Graf's method

- İletişim adresi: Dr. Mehmet Müfit Orak, Fatih Sultan Mehmet Eğitim ve Araştırma Hastanesi, Ortopedi ve Travmatoloji Kliniği. E5 Karayolu Üzeri İçerenköy, Ataşehir, İstanbul Tel: 0216 - 5783000 e-posta: mehmetmufitorak@yahoo.com

- Geliş tarihi: 3 Eylül 2014 Kabul tarihi: 3 Ey/ül 2014

Tedavinin başarısını belirleyen en önemli etmen, tanının erken konmasıdır. Yaşamın ilk aylarında tedavi edilmesi durumunda sekelsiz iyileşmesi mümkün iken, geç kalınmış olgularda tedavide ciddi zorluklarla karşılaşilır ve sekeller kalır. ${ }^{[2]}$

GKD erken tanısında yıllar boyunca öncelikli tarama metodu olarak Barlow ve Ortolani testleri kullanılmıştır. Ancak günümüzdeki çalışmalar bu testlerin GKD'yi saptamada yetersiz kaldığını göstermiştir. Barlow ve Ortolani testlerinin özgünlüğü yüksek (>99\%) olmasına rağmen, duyarlılığı düşük $(60 \%)$ olarak bulunmuş̧tur. ${ }^{[5,6]}$ 
Anteroposterior radyografiler altı aydan büyük bebeklerde tanı için önceliklidir. ${ }^{[7]}$ Ancak, femur başı epifizinin 4-6 aydan önce ossifiye olmaması nedeniyle, konvansiyonel radyografilerin ilk altı aylık dönemde tanısal amaçlı kullanılması yetersiz kalabilir.

GKD erken tanısında kalça ultrasonografisi (US) Graf tarafından geliştirilmiş olup, ilerleyen yıllar içerisinde geniş kabul görerek pekçok ülkede GKD taramasında kullanılmaya başlanmıştır. ${ }^{[8]}$ Günümüzde GKD tanısında ve takibinde US en sık kullanılan radyolojik yöntem olup, erken dönemde fizik muayene ve konvansiyonel radyografi ile saptanamayan displaziler US ile saptanır hale gelmiştir. ${ }^{[9-13]}$

Kalça US'si 0-6 aylık bebeklere yapılır. Büyüyen bebekte kalça epifiz çekirdeğinin kalsifiye olması ile asetabulumun en derin noktasının görüntülenmesi zorlaşır. Bunun sonucunda, kalça US'si altıncı aydan sonra etkinliğini kaybeder. En ideal US zamanı ise 4-6 hafta olarak bildirilmiştir. ${ }^{[13]}$ Bunun nedeni olarak ise, başlangıçta immatür olan kalçaların \%90'nın yaşamın ilk altı haftasında spontan olarak matüritesine ulaşması gösterilmiştir. ${ }^{[14]}$

\section{Kalça ultrasonografisi teknikleri}

Kalça ultrasonografisinin GKD tanısı amacıyla yaygın kullanımıyla birlikte, Graf'ın geliştirmiş olduğundan farklı teknikler de ortaya konmuştur. ${ }^{[8,15-19]}$ Bu yöntemler görünüme, görüntünün planına (aksiyel, koronal veya sagittal) ve görüntülemenin yönüne (anterior, lateral, inferior) göre farklılık gösterir. Bu yöntemlerin bir diğer farkı da değerlendirmenin kalça morfolojisi veya kalça stabilitesine odaklanmasıdır.

Graf'ın tekniği kuşkusuz en yaygın yöntem olup, pekçok ülkede sıklıkla kabul görüp uygulanmaktadır. ${ }^{[8]}$ Statik bir yöntem olan bu teknikte, lineer prob ile elde edilen lateral koronal görüntüler ile asetabulum morfolojisi değerlendirilir. Graf, tekniğinin belli kalıplar içinde uygulanması gerektiğini, referans noktalar doğru bir şekilde elde edildiğinde tekniğin kişiden bağımsız olduğunu, görüntülerin kişiler tarafından farklı yorumlanamayacağını ve oldukça güvenilir olduğunu savunmaktadır. ${ }^{[13]}$

1984 yılında Harcke tarafindan tanımlanan teknikte ise, bebek supin veya lateral dekübit pozisyonundayken, yine lineer prob ile lateral olarak görüntüleme yapılır. ${ }^{[15]} \mathrm{Bu}$, femur başının istirahat durumunda ve Barlow-Ortolani manevraları gibi provokasyon testleri ile stres altındaki pozisyonunu değerlendiren, herhangi bir ölçüm yapılmayan dinamik bir yöntemdir. Bu yöntem subjektif olup, yorumlamada farklılıklar olabileceği unutulmamalıdır.
Saies, Harcke'nin tekniğine femur başı dislokasyonunun ölçümünü ekleyerek modifiye etmiştir. ${ }^{[16]}$ Bebek supin pozisyonda ve kalça fleksiyonda iken, kalçanın transvers lateral görüntüsü elde edilir. Barlow manevrasına benzer şekilde arkaya doğru baskı uygulanarak femur başı posteriora deplase edilmeye çalışılırken görüntü elde edilir. Bu yöntemin uygulanabilmesi için iki kişiye ihtiyaç vardır.

Tersejen yönteminde, bebek supin pozisyonda iken, lineer veya oval prob ile lateral yaklaşımla, frontal ve transvers planlarda statik ve dinamik görüntü elde edilir. ${ }^{[17]}$ Bu teknikte, femur başının örtünümü sayısal olarak değerlendirilir. Buna göre, başın örtünümü kızlarda $\% 55$, erkeklerde ise $\% 57$ olarak bulunmuştur.

Suzuki ve arkadaşları ise, her iki kalçanın lineer prob ile simultan olarak anterior aksiyel görüntülerini elde ettikleri başka bir teknik tanımlamışlardır. ${ }^{[18]}$ Bu yöntemle, kalçanın lateral deplasmanını saptayabildiklerini belirtmişlerdir. Bebekler supin pozisyonda, kalçalar ekstansiyon ve fleksiyon-abduksiyon pozisyonunda iken değerlendirilirler.

Rosendhal ise, Graf'ın yöntemini modifiye Barlow manevrası ile tamamlamıştır ${ }^{[19]}$ ve kalça morfolojisi ve kalça stabilitesini ayrı ayrı değerlendirmektedir. Standart koronal planda $\alpha$ açısı ile morfolojiye bakarken, Barlow ile stres vererek stabiliteyi değerlendirmiştir.

Biz teknik olarak ülkemizde de geniş kabul gören Graf metodunu ayrıntılı inceleyeceğiz.

\section{GRAF US UYGULAMA TEKNIĞi (20)}

\section{Gereç ve ortam}

Kalça US uygulaması için, US cihazının yanında, çocuğun lateral dekübit pozisyonunda yatmasını sağlayan muayene masasına gereksinim vardır (Şekil 1). Bu masa bebeği tam lateral pozisyonda tutmalıdır. Tam lateral yatan bebeğin kalçasından koronal kesit görüntü alabilmek için probun eğim yapmaması gereklidir. Bu amaçla prob tutucu kullanılması uygundur (Şekil 1). Bebeğin huzursuz olmaması için ortamın uygun ısıda ve sessiz olması, bebeğin muayeneye hazırlanmış olması gereklidir. Bebeğin sakinleşmesi için inceleme esnasında bebeğin biberonla beslenmesi oldukça etkili bir yöntemdir. Ayrıca huzursuzlanan bebeğin emme refleksinin uyarılarak annesinin parmağını emmesi de bebeği sakinleştirmek için kullanılabilir.

\section{Makine ayarları}

İncelemeye başlamadan önce kullanılacak cihazın kılavuz kitapçı̆̆ı dikkatlice okunmalı ve ayarları tecrübe edilmelidir. 


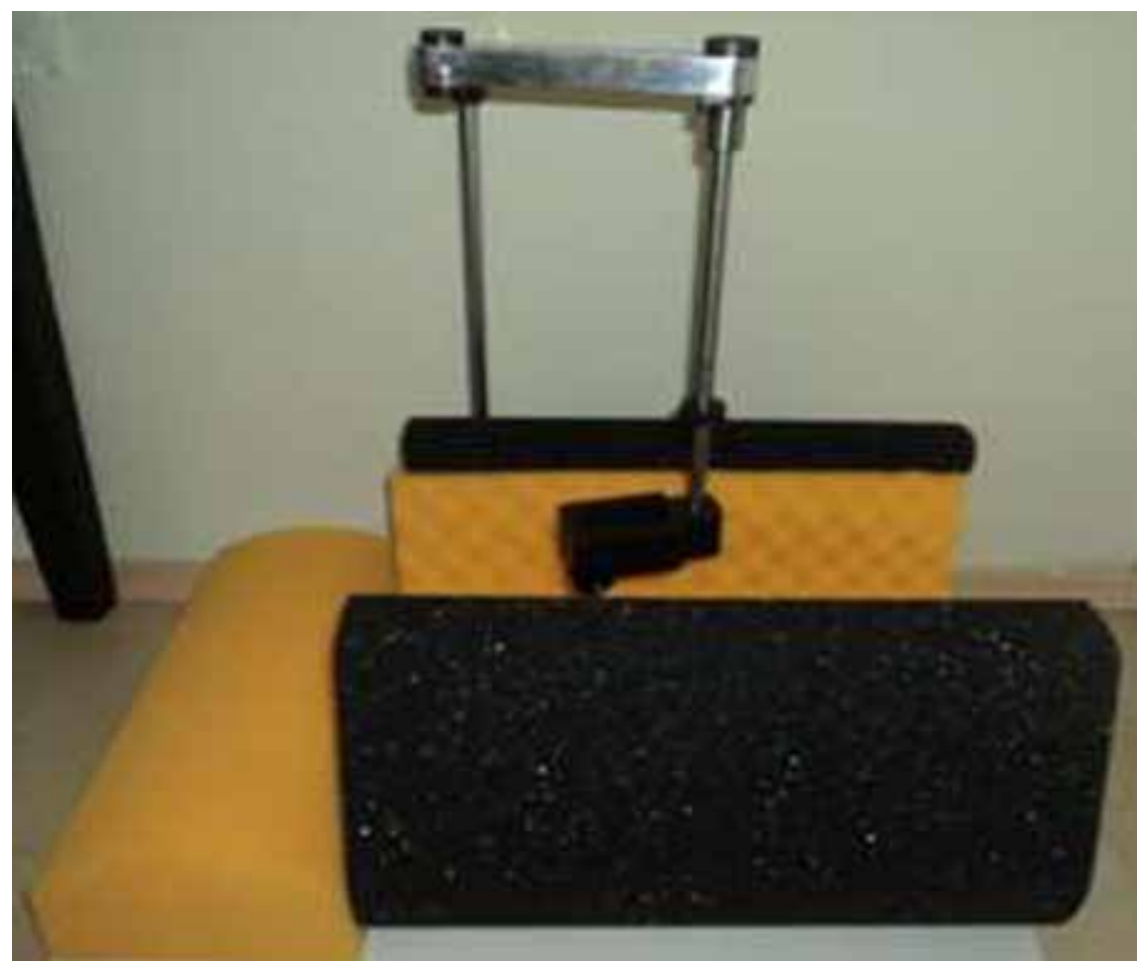

Şekil 1. Kalça US masası ve prob tutucu.

\section{US cihazının prob seçimi}

Kalça incelemesi için lineer prob seçilmelidir. Eğer US cihazının yazılımında ortopedik inceleme seçimi mevcut ise tercih edilmelidir (Şekil 2).

\section{Frekans seçimi}

Seçilen frekans değeri arttıkça yüzeyel doku görüntüsü netleşir. Yenidoğan ve prematüre incelemelerinde $10 \mathrm{MHz}$ seçilirken, tombul ve altı aylık bebeklerde 5 $\mathrm{MHz}$ tercih edilmelidir (Şekil 2).

\section{Odak seçimi}

Kalça sonografik incelemesinde tek odaklı inceleme tercih edilmeli ve odak seviyesi iliak kanat ekojenitesi ile aynı olmalıdır (Şekil 2).

\section{Derinlik ve kontrast seçimi}

Derinlik ayarı, asetabulumun en derin noktasını görüntüleyecek en yüzeyel ayarda olmalıdır. Böylece en büyük kalça imajı elde edilmiş olur. Kontrast seçimi ise görüntüde anatomik noktaların ayırt edilmesini sağlayan oranda olmalıdır. Ayrıca ilk görüntüden baskı alınarak ekrandaki görüntünün kağıda yansıması kontrol edilmelidir.

\section{Uygulama}

Bebek muayene masasına yatırıldıktan sonra ultrasonografi uygulayıcısı bir eliyle bebeğin ekstremitesini

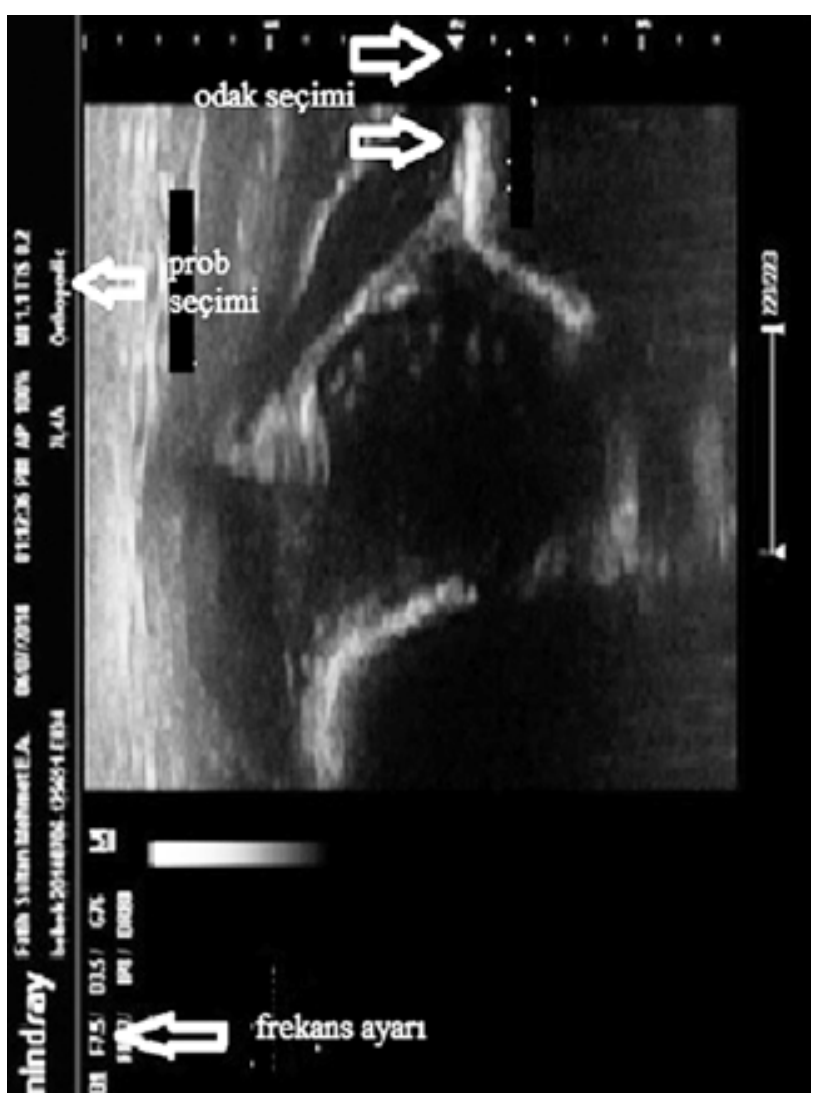

Şekil 2. Sonografik görüntüde makine ayarlarının kontrolü. 
$20-30^{\circ}$ fleksiyon, $5-10^{\circ}$ iç rotasyonda sabitlemeli, diğer eliyle probu kullanmalıdır. Uygun görüntüyü elde ettiğinde görüntüyü dondurmak için ayakla kumanda edilen freze cihazı veya asistan yardımına ihtiyacı vardır.

Uygun pozisyonda yatan bebeğe uygun makine ayarları yapıldıktan sonra sonografik muayene başlatılabilir. Önce büyük trokanter palpe edilir ve prob yere ve bebeğin gövdesine paralel olarak büyük trokanter üzerine yerleştirilir. Prob öne arkaya ilerletilerek kalça imajı elde edilir. Tüm görüntüler sağ kalça imajı olarak elde edilmelidir. Asetabulum en derin noktası görüntülendiğinde, iliak kanadın vertikal görüntüsünü yakalamak için proba rotasyon yaptırılır. Uygun görüntü elde edildiği anda görüntü durdurulur. Elde edilen görüntünün yeterli olduğuna karar verilirse yazıcıdan çıktı alınır. Bu işlem her kalça için en az iki kez tekrarlanmalıdır. Elde edilen görüntülerin açı ölçümü yapılarak sonografik muayene tamamlanır.

\section{Dökümantasyon}

\section{Raporlama}

Bebeğin kimlik bilgileri, doğum tarihi, sonografik inceleme tarihi, morfolojik tanımlama, açısal ölçüm sonuçları ve kalça tiplendirmesi ile gerekli önerileri içeren rapor düzenlenmelidir. Rapora ayrıca standart iki adet sonografik görüntü ilave edilmelidir.

\section{Arşivleme}

Hastanın demografik bilgileri, risk etmenleri ve fizik muayene bulgularını içeren kaydı arşivlenmelidir. Ayrıca yasal problemlere karşı bir adet sonografik görüntünün arşivlenmesi uygun olacaktır.

\section{Ultrasonografik anatomi}

US'nin avantajı, hayatın erken döneminde kemikleşmesi tamamlanmamış kalça ekleminde yumuşak dokuların değerlendirmesine olanak sağlamasıdır. Elde edilen US görüntüsünde kalça anatomisinin görüntülenmesi ve tanımlanması gereklidir. Uygun bir kalça US görüntüsünde, femur osteokondral bileşkesi (1), sinoviyal katlantı (2), eklem kapsülü (3), labrum (4), perikondriyal açıklık (5), perikondriyum (6), iliak kanat (7), asetabular köşe (8), asetabular tavan (9) ve iliak kemiğin en derin noktası (10) görüntülenebilir (Şekil 3).

\section{STANDART PLAN}

Sonografik değerlendirmeler, bu değerlendirmeleri yapan radyoloğa bağlı olarak değişiklik gösterebilir. Ancak, Graf yönteminde kalça sonografik incelemesi nesnel değerlendirmeye imkan sağlar. Nesnel değerlendirmenin yapılabilmesi için standart görüntüye gereksinim vardır. Anatomik yapıların tanımlaması yapılabilen US görüntüsünde; vertikal yerleşimli iliak kanat (1), asetabulumun en derin noktası (2) ve labrumun (3) olması standart plan varlığı için gereklidir (Şekil 4).

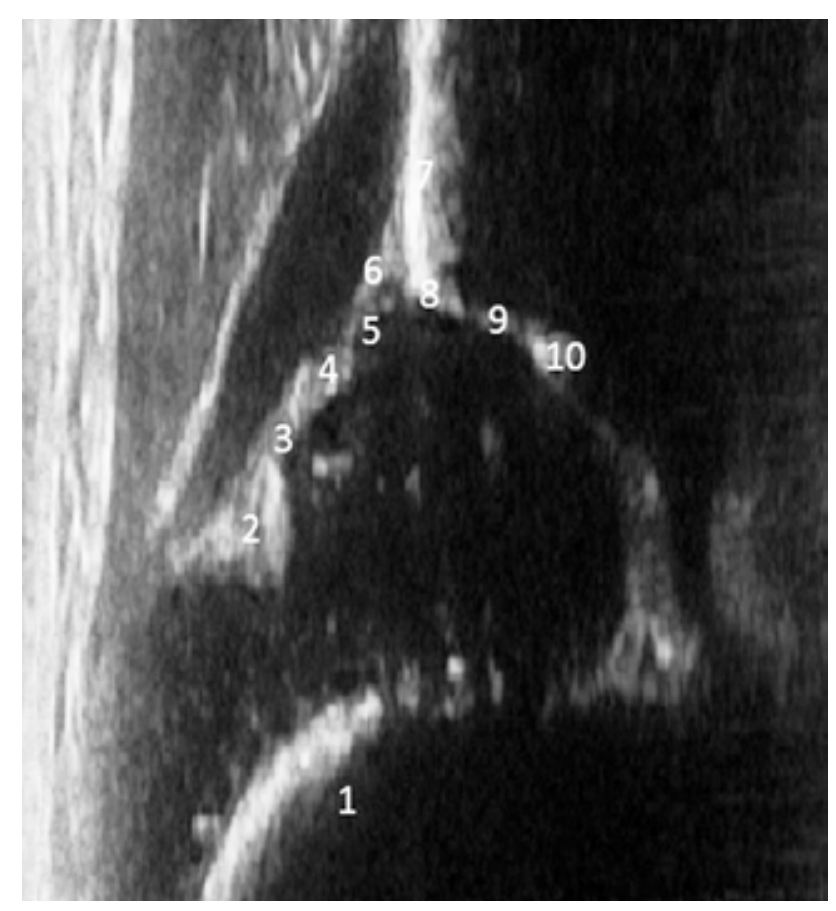

Şekil 3. Sonografik anatomi.

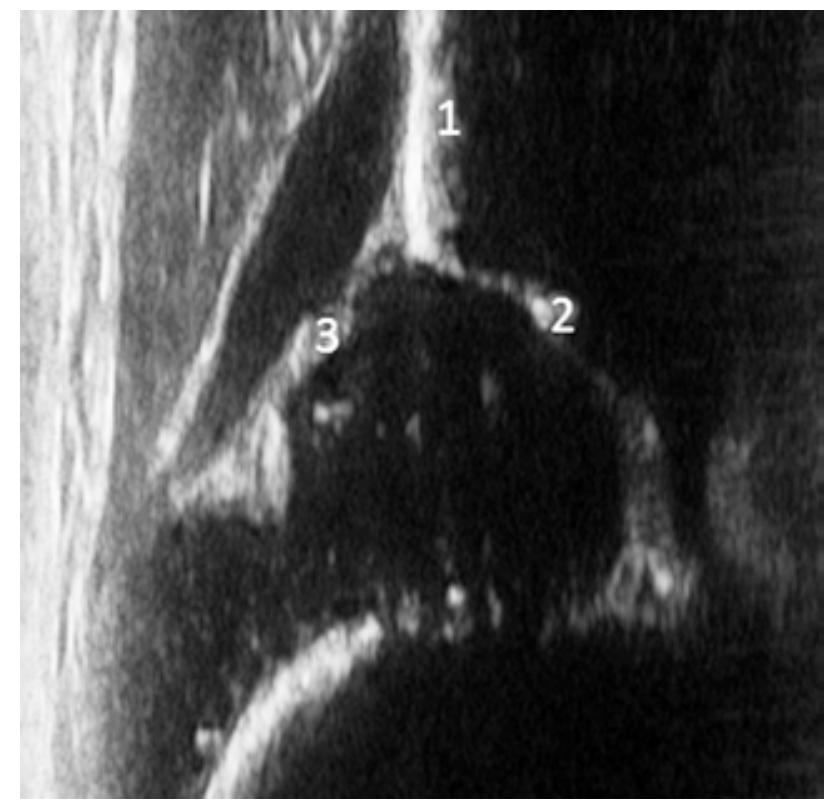

Şekil 4. Standart plan. 


\section{AÇISAL DEĞERLENDIRME}

US görüntüsünde anatomik tanımlama yapılmış ve standart plan elde edilmiş ise (Şekil 3, 4), görüntü açısal değerlendirmeye tabi tutulur. Alfa $(\alpha)$ ve beta $(\beta)$ açıları çizilerek kalça açısal olarak yorumlanır.

\section{$\alpha$ açısı}

Asetabulumun en derin noktasının distal ucundan kemik köşeye çekilen teğet ile iliak kanat vertikal aksı arasındaki açıdır. Asetabulumun kemik çatısının değerlendirilmesinde kullanılır (Şekil 5).

\section{$\beta$ açıII}

Labrum orta noktasından asetabular köşeye çizilen hat ile iliak kanat vertikal aksı arasındaki açıdır. Kıkırdak çatıyı değerlendirmede kullanılır (Şekil 5).

\section{MORFOLOJIK DEĞERLENDIRME}

Elde edilen sonografik görüntünün değerlendirmesinde kemik çatı, kemik köşe ve kıkırdak çatının tanımlaması yapılır. Kemik çatı "iyi", "yetersiz" ve "kötü" olarak; kemik köşe "köşeli veya künt", "yuvarlak" ve "düzleşmiş"; kıkırdak çatı ise femur başını kapsamasına göre "örtüyor" ve "deplase" olarak tanımlanır ve kaydedilir. Morfolojik tanımlama ile açısal tiplendirmelerin uyumluluğu kontrol edilir.

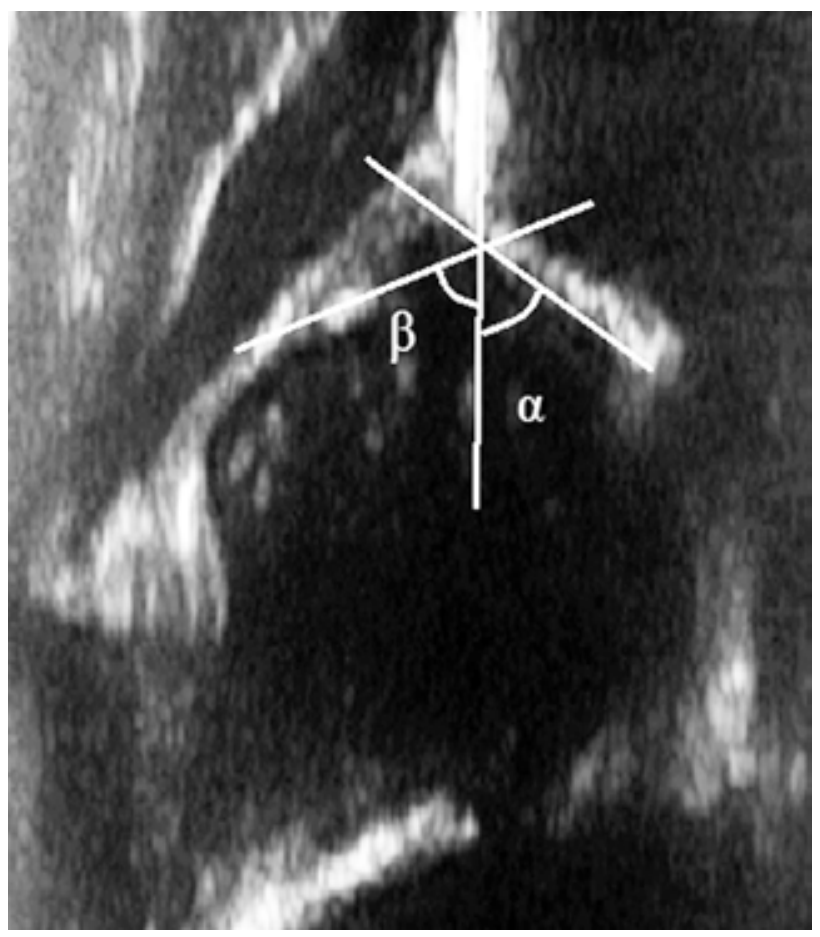

Şekil 5. $\alpha$ ve $\beta$ açılarının çizimi.

\section{TIPLENDIRMELER}

Kalça, elde edilen $\alpha$ ve $\beta$ açısal ölçümü esas alınarak Graf tarafından tanımlanan sonometreye göre tiplendirilir (Şekil 6) (Tablo 1).

\section{Tip I (matür) kalça}

$\alpha$ açısı $60^{\circ}$ ve üstündedir. $\beta$ açısı $55^{\circ}$ den düşük ise Tip la, büyük ise Tip lb olarak tanımlanır. Tip la ve Tip Ib kalçaların klinik olarak farkı yoktur. Her iki kalça tipi de kalçanın matürasyonunu tamamladığını ve normal olduğunu ifade eder (Şekil 7).

\section{Tip Ila/Ilb kalça}

$\alpha$ açısı 50-59'dir. Her iki tip kalça da sentrik yerleşimli ve redüktedir. Tip Ila ile Tip Ilb arasındaki ayrım bebeğin kronolojik yaşına göre yapılır. Bebeğin kronolojik yaşı 12 haftadan küçük ise Tip Ila, büyük ise Tip IIb olarak sınıflandırılır (Şekil 8, 9). Tip Ila fizyolojik immatür kalçadır ve takip edilerek matürasyona kadar izlenir. Tip Ilb kalça gecikmiş immatür kalçadır ve tedavi edilmelidir.

Tip Ila kalçalar kronolojik yaş ve $\alpha$ açısı esas alınarak Tip Ila(-) ve Tip Ila(+) olarak ikiye ayrılır. Tip Ila kalçalarda $\alpha$ açısı değeri ile kronolojik yaş arasında lineer ilişki vardır. Kronolojik yaş iz düşümüne göre olması gereken $\alpha$ açısı değerinden daha düşük $\alpha$ açısına sahip bebekler Tip Ila(-) olarak tiplendirilir. Bu bebeklerin, kronolojik yaşı 12 hafta olduğunda matürasyona ulaşamayacakları ve Tip Ilb kalça (gecikmiş immatürite) gelişeceği öngörülür. Bu grup kalçaların tedavi edilmesi ve Tip Ilb kalça gelişimine izin verilmemesi önerilir. Tip Ila(-) kalça tiplendirmesi için bebeğin kronolojik yaşının 6 haftadan büyük olması gereklidir (Şekil 10).

\section{Tip Ilc kalça}

$\alpha$ açısı $43-49^{\circ}$ arasında $\beta$ açısı $77^{\circ}$ 'den küçük bebekler Tip Ilc olarak sınıflandırılır (Şekil 11). Tip Ilc kalçalar ultrasonografi esnasında dinamik muayeneye tabi tutulurlar. Kalça sonografik olarak görüntülenirken, dizden kalçaya doğru femur aksı boyunca kuvvet uygulanır. Bu esnada labrumun yer değişimi ( $\beta$ açısındaki değişme) izlenir. Eğer kompresyonla $\beta$ açısı $77^{\circ}$ 'nin üstüne çıkıyorsa, kalça Tip Ilc instabil olarak tanımlanır. Kompresyonla labrum yer değiştirmiyorsa, Tip Ilc stabil olarak tanımlanır. Tip Ilc kalçalar sentrik kalçalardır. Displazi nedeniyle tedavi edilmeleri gerekir.

\section{Tip D kalça}

$\alpha$ açısı $43-49^{\circ}$ arasında $\beta$ açısı $77^{\circ}$ 'den büyük bebekler Tip D olarak sınıflandırılır (Şekil 12). Kalça displazisinde desentrik kalçanın ilk aşamasıdır. Kalça instabildir. 


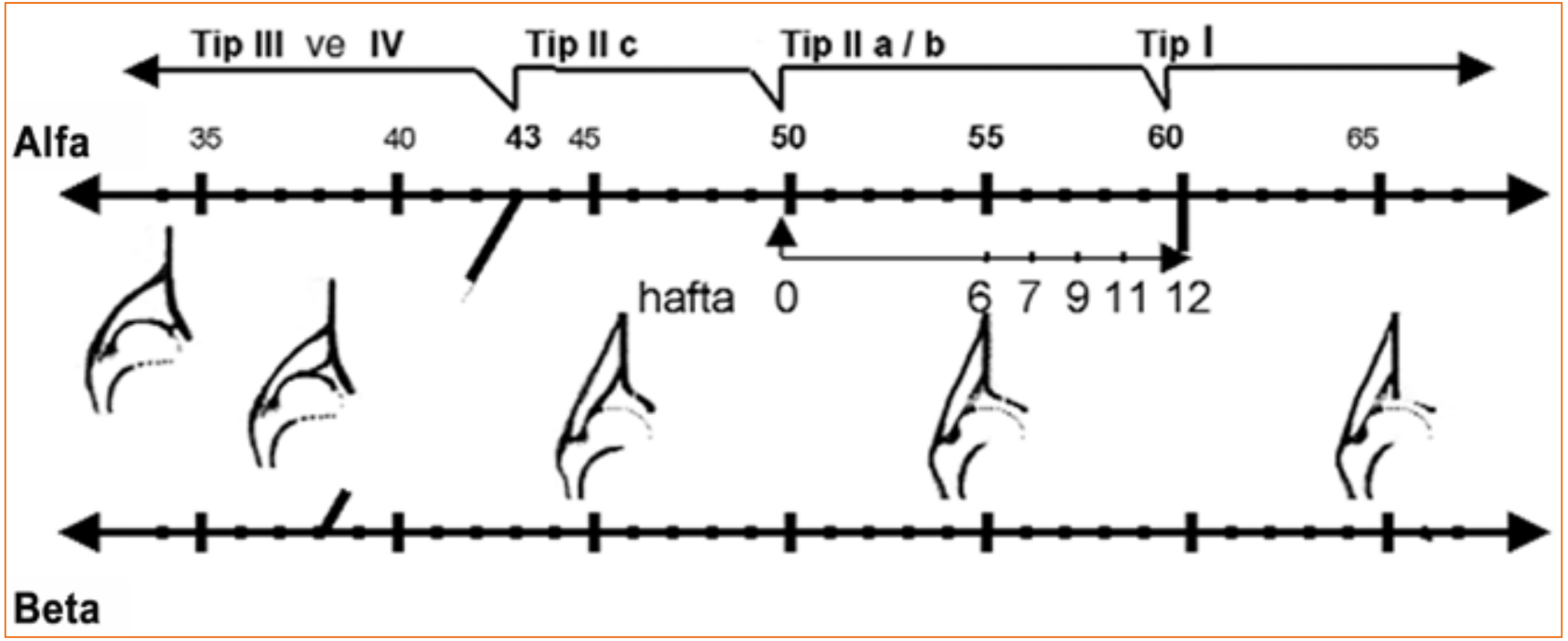

Şekil 6. Sonogram. ${ }^{[20]}$

Tablo 1. Graf'a göre ultrasonografik kalça tiplendirmesi

\begin{tabular}{|c|c|c|c|c|}
\hline Kalça tipi & Kronolojik yaş & Kemik çatı ( $\alpha$ açısı) & Kemik köşe & Kıkırdak çatı ( $\beta$ açısı) \\
\hline Tip I & Tüm yaşlar & İyi $\alpha \geq 60^{\circ}$ & Köşeli/yuvarlak & $\begin{array}{c}\text { Femur başını örtüyor } \\
\beta<55^{\circ} \text { Tip la } \\
\beta \geq 55^{\circ} \text { Tip lb }\end{array}$ \\
\hline Tip IIa(+) & 0-12 Hafta & $\begin{array}{c}\text { Yetersiz } \\
\alpha=50-59^{\circ}\end{array}$ & Yuvarlak & Femur başını örtüyor \\
\hline Tip IIa(-) & 6-12 Hafta & $\begin{array}{c}\text { Yetersiz } \\
\alpha=50-59^{\circ}\end{array}$ & Yuvarlak & Femur başını örtüyor \\
\hline Tip IIb & $\geq 12$ Hafta & $\begin{array}{c}\text { Yetersiz } \\
\alpha=50-59^{\circ}\end{array}$ & Yuvarlak & Femur başını örtüyor \\
\hline Tip IIc & Tüm yaşlar & $\begin{array}{l}\text { Ciddi yetersiz } \\
\alpha=43-49^{\circ}\end{array}$ & Yuvarlak-düzleşmiş & Femur başını örtüyor $\beta<77^{\circ}$ \\
\hline Tip D & Tüm yaşlar & $\begin{array}{l}\text { Ciddi yetersiz } \\
\alpha=43-49^{\circ}\end{array}$ & Yuvarlak-düzleşmiş & Femur başını örtüyor $\beta \geq 77^{\circ}$ \\
\hline Tip IIla & Tüm yaşlar & $\begin{array}{l}\text { Kötü } \\
\alpha<43\end{array}$ & Düzleşmiş & $\begin{array}{c}\text { Yukarıya itilmiş (deplase) } \\
\text { Dejenerasyon yok }\end{array}$ \\
\hline Tip IIIb & Tüm yaşlar & $\begin{array}{l}\text { Kötü } \\
\alpha<43\end{array}$ & Düzleşmiş & $\begin{array}{c}\text { Yukarıya itilmiş (deplase) } \\
\text { Dejenerasyon var }\end{array}$ \\
\hline Tip IV & Tüm yaşlar & $\begin{array}{l}\text { Kötü } \\
\alpha<43\end{array}$ & Düzleşmiş & Aşağıya itilmiş (deplase) \\
\hline
\end{tabular}

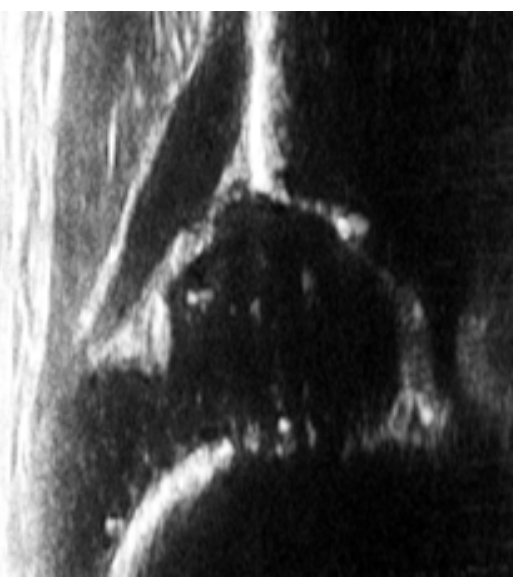

Şekil 7. Tip I (matür) kalça.

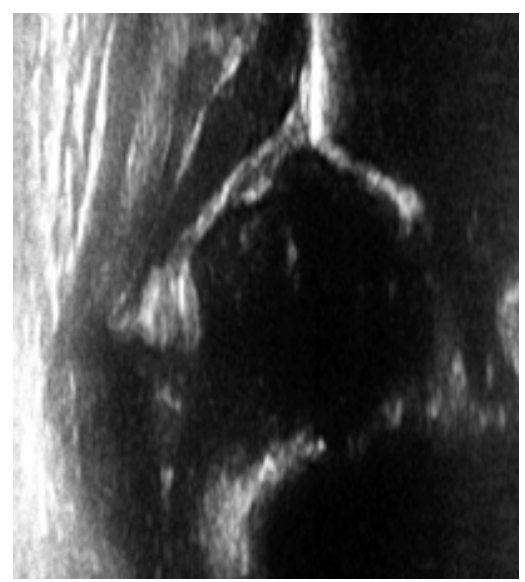

Şekil 8. Tip lla kalça (5 günlük bebek).

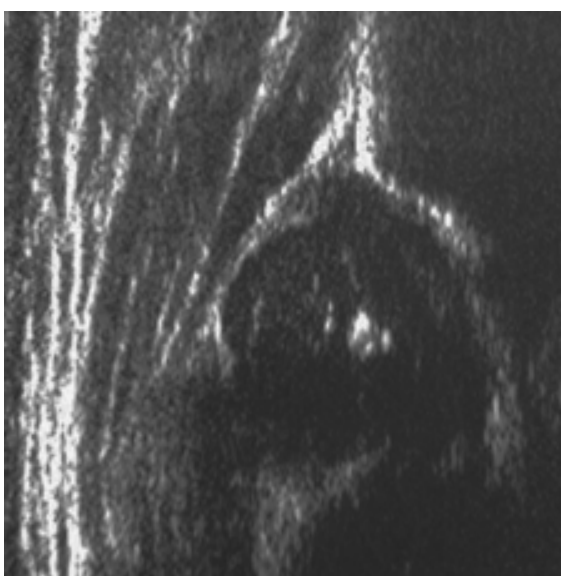

Şekil 9. Tip Ilb kalça (18 haftalık bebek). 


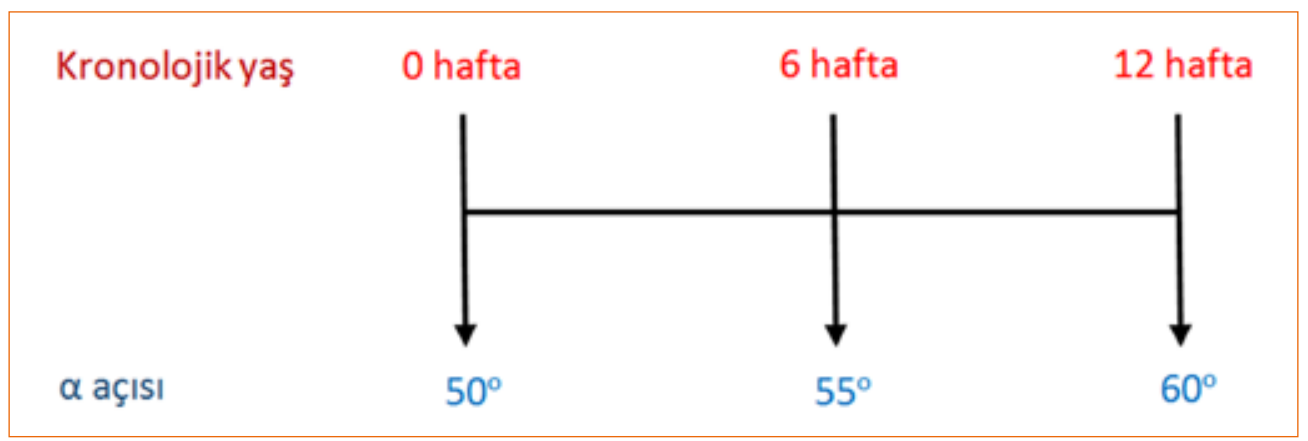

Şekil 10. Tip Ila kalçalarda kronolojik yaş ve $\alpha$ açısı değişimi.

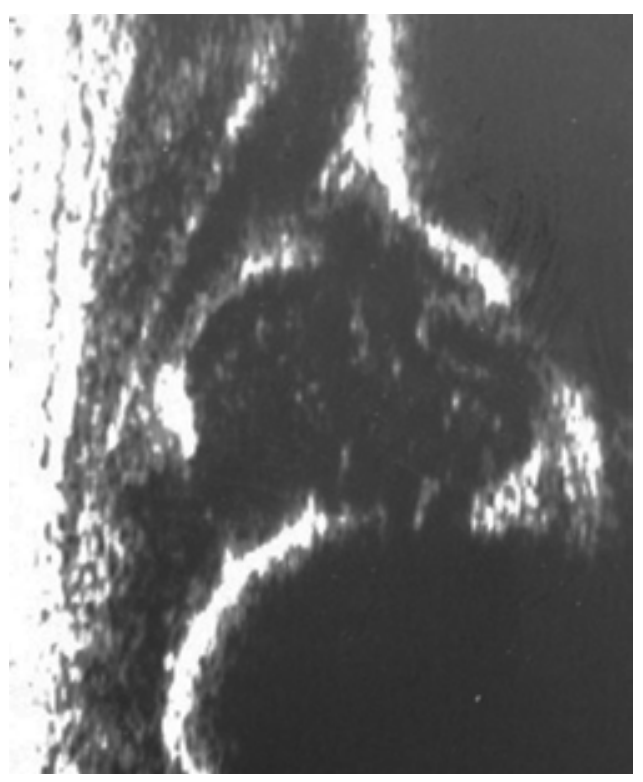

Şekil 11. Tip Ilc kalça.

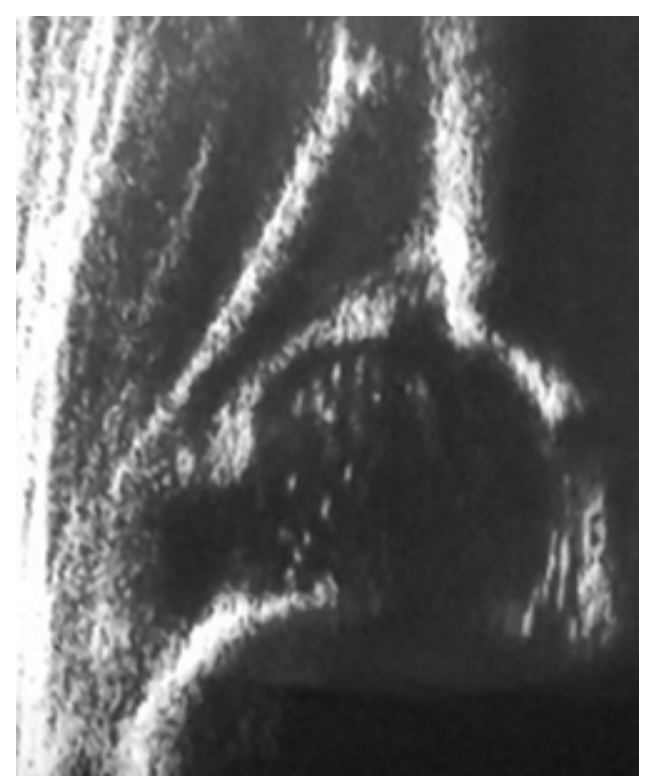

Şekil 12. Tip D kalça.

\section{Tip III/IV kalça}

$\alpha$ açısı $43^{\circ}$ 'den küçük kalçalar Tip III ve Tip IV kalça olarak sınıflandırılır. $\beta$ açısı bu grup kalçalarda $77^{\circ}$ 'den fazladır. Elde edilen sonografik görüntünün morfolojik değerlendirmesi tiplendirmede esastır. Tip III kalçalarda kıkırdak tavan femur başının üstündedir. US'de perikondrium imajı yukarıdan aşağıya doğrudur. Tip IIla kalçalarda perikondrial kıkırdakta ekojenite artışı (dejenerasyon) yoktur (Şekil 13). Tip IIIb kalçalarda ise perikondrial kıkırdakta dejenerasyon vardır (Şekil 14). Tip IV kalçalarda kıkırdak çatı femur başının inferiorundadır. US görüntüsünde perikondrium imajı yatay veya aşağıdan yukarıya doğrudur (Şekil 15). Tip IV kalçalarda asetabulum ve femur proksimali aynı koronal düzlemde olmadığı için tüm anatomik yapılar aynı kesitte görüntülenemeyebilir; ayrıca Tip IV görüntülerde standart plan aranmaz. Tip III ve Tip IV kalçalar tedavi gerektiren kalçalardır.

\section{TARAMADA ULTRASONOGRAFININ ROLÜ}

GKD erken tanısında ultrasonografik taramanın sağlamış olduğu başarı pekçok çalışma ile ortaya konmuştur. Özellikle sessiz displazilerde, sonografik tarama en önemli araçtır. Fizik muayene ile saptanamayan displazik kalçalar ultrasonografik olarak ortaya konabilir. ${ }^{[9]}$

Tartışmalar ise sıklıkla, bu uygulamanın selektifya da universal yapılması üzerinde yoğunlaşmaktadır.[1,21,22] Yarar-maliyet analizi yapıldığında, pozitif fizik muayene bulgusu ve risk etmenleri olan bebeklerin kalça US'si ile taranmasının daha uygun olduğunu gösteren, selektif taramayı savunan çalışmalar mevcuttur. ${ }^{[1,23]}$

Buna karşılık Thaler ve arkadaşları, universal taramanın maliyeti arttırdığını kabul etmekle birlikte, yine de bunu savunmuşlardr. ${ }^{[24]}$ Avusturya ve Almanya'da 1990'lı yıllarda başlatılan evrensel tarama programları, cerrahi girişime olan gereksinimi dramatik biçimde 


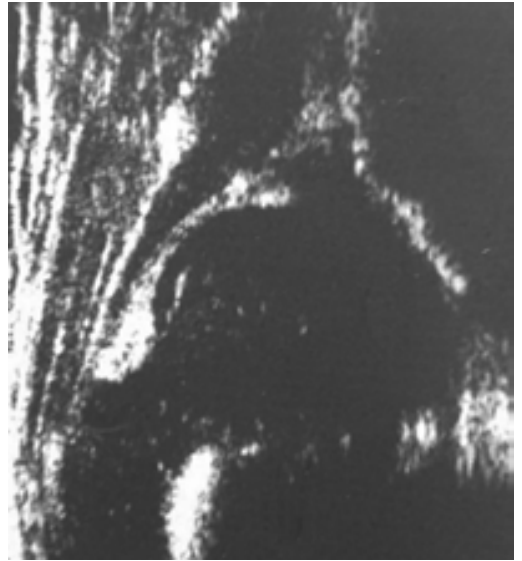

Şekil 13. Tip Illa kalça.

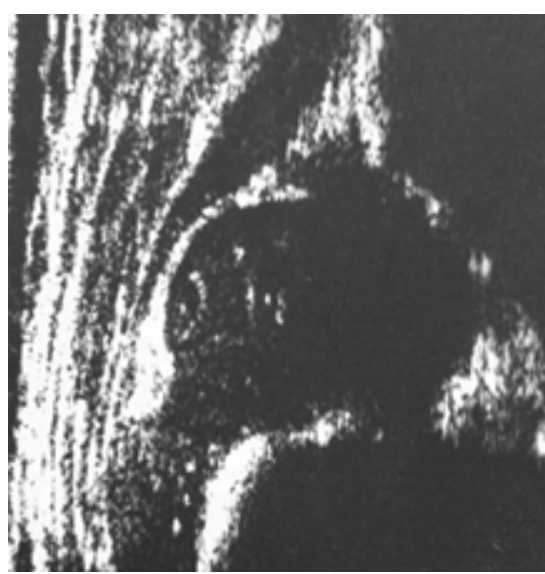

Şekil 14. Tip IIIb kalça.

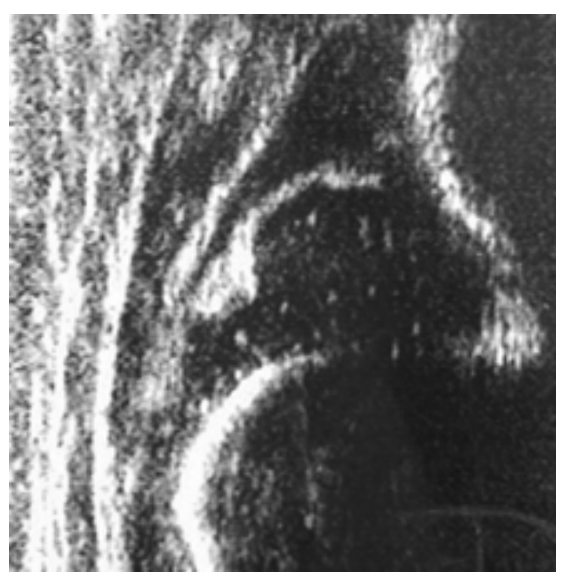

Şekil 15. Tip IV kalça. azaltmıştır. Bunun neticesinde, açık redüksiyon oranı binde 0,13 'e kadar azaltılmıştır. ${ }^{[13]}$

\section{SONUÇ}

Ülkemizde yenidoğan US taraması ile yapılmış sıklık çalışmaları mevcuttur. Bu çalışmalarda \%0,86-17 arasında değişen oranlarda kalça displazi sıklığı verilmiştir. ${ }^{[25-30]}$ Yılda ortalama 1.200.000 canlı doğum gerçekleşen ülkemizde, her yıl yaklaşık 15.000 bebek GKD'li olarak doğmaktadır. ${ }^{[31]}$

GKD yenidoğanlarda önemli bir sağlık sorunu olmaya devam etmektedir. Kalça US'si, bu sorunun erken tanısında en etkin yöntemdir. Kalça US'sinin yaygınlaştırılması, GKD'de erken tanı konarak daha başarılı tedavi sonuçları elde etmeyi sağlayacaktır.

\section{Teşekkür}

Yazının hazırlanmasındaki katkılarından dolayı sayın Prof. Dr. Tuncay Centel'e teşekkür ederiz.

\section{KAYNAKLAR}

1. Mahan ST, Katz JN, Kim YJ. To screen or not to screen? A decision analysis of the utility of screening for developmental dysplasia of the hip. J Bone Joint Surg Am 2009;91(7):170519. CrossRef

2. Keller MS, Nijs EL. The role of radiographs and US in developmental dysplasia of the hip: how good are they? Pediatr Radiol 2009;39 Suppl 2: S211-5. CrossRef

3. Hoaglund FT, Steinbach LS. Primary osteoarthritis of the hip: etiology and epidemiology. J Am Acad Orthop Surg 2001;9(5):320-7.

4. Furnes O, Lie SA, Espehaug B, Vollset SE, Engesaeter LB, Havelin LI. Hip disease and the prognosis of total hip replacements. A review of 53,698 primary total hip replacements reported to the Norwegian Arthroplasty Register 1987-99. J Bone Joint Surg Br 2001;83(4):579-86.
5. Jones $D$. An assessment of the value of examination of the hip in the newborn. J Bone Joint Surg Br 1977;59(3):318-22.

6. Macnicol MF. Results of a 25-year screening programme for neonatal hip instability.J Bone Joint Surg $\mathrm{Br}$ 1990;72:1057-60.

7. Grissom L, Harcke HT, Thacker M. Imaging in the surgical management of developmental dislocation of the hip. Clin Orthop Relat Res 2008;466(4):791-801. CrossRef

8. Graf R. The diagnosis of congenital hip-joint dislocation by the ultrasonic Combound treatment. Arch Orthop Trauma Surg 1980;97(2):117-33.

9. Dogruel $\mathrm{H}$, Atalar $\mathrm{H}$, Yavuz OY, Sayli U. Clinical examination versus ultrasonography in detecting developmental dysplasia of the hip. Int Orthop 2008;32(3):415-9.

10. Portinaro NM, Pelillo F, Cerutti P. The role of ultrasonography in the diagnosis of developmental dysplasia of the hip. J Pediatr Orthop 2007;27(2):247-50.

11. Wientroub S, Grill F. Ultrasonography in developmental dysplasia of the hip. J Bone Joint Surg Am 2000;82-A(7) :1004-18.

12. Kamath S, Mehdi A, Wilson N, Duncan R. The lack of evidence of the effect of selective ultrasound screening on the incidence of late developmental dysplasia of the hip in the Greater Glasgow Region. J Pediatr Orthop B 2007;16(3):189-91.

13. Graf R. The use of ultrasonography in developmental dysplasia of the hip. Acta Orthop Traumatol Turc 2007;41 Suppl 1:6-13.

14. Puhan MA, Woolacott N, Kleijnen J, Steurer J. Observational studies on ultrasound screening for developmental dysplasia of the hip in newborns: a systematic review. Ultraschall Med 2003;24(6):377-82.

15. Harcke HT, Clarke NM, Lee MS, Borns PF, MacEwen GD. Examination of the infant hip with real-time ultrasonography. J Ultrasound Med 1984;3(3):131-7.

16. Saies AD, Foster BK, Lequesne GW. The value of a new ultrasound stress test in assessment and treatment of clinically detected hip instability. J Pediatr Orthop 1988;8(4):436-41.

17. Terjesen $T$, Bredland $T$, Berg V. Ultrasound for hip assessment in the newborn. J Bone Joint Surg Br 1989;71(5):767-73.

18. Suzuki S, Kasahara $\mathrm{Y}$, Futami $\mathrm{T}$, Ushikubo $\mathrm{S}$, Tsuchiya $\mathrm{T}$. Ultrasonography in congenital dislocation of the hip. Simultaneous imaging of both hips from in front. J Bone Joint Surg Br 1991;73(6):879-83. 
19. Rosendahl K, Markestad T, Lie RT. Ultrasound in the early diagnosis of congenital dislocation of the hip: the significance of hip stability versus acetabular morphology. Pediatr Radiol 1992;22(6):430-3.

20. Graf R. Kalça ultrasonografisi el kitabı. Ultrasonografi ile Gelişimsel Kalça Displazisinin Tanısı ve Tedavinin Planlanması. Türkçe çeviri, 1. Basım. İstanbul: Avrupa Yayınları; 2001.

21. Laborie LB, Engesæter $\varnothing \varnothing$, Lehmann TG, Eastwood DM, Engesæter LB, Rosendahl K. Screening strategies for hip dysplasia: long-term outcome of a randomized controlled trial. Pediatrics 2013;132(3):492-501. CrossRef

22. Shorter D, Hong T, Osborn DA. Cochrane Review: Screening programmes for developmental dysplasia of the hip in newborn infants. Evid Based Child Health 2013;8(1):11-54. CrossRef

23. Desprechins B, Ernst C, de MeyJ. Screening for developmental dysplasia of the hip. JBR-BTR 2007;90(1):4-5.

24. Thaler M, Biedermann R, Lair J, Krismer M, Landauer F. Costeffectiveness of universal ultrasound screening compared with clinical examination alone in the diagnosis and treatment of neonatal hip dysplasia in Austria. J Bone Joint Surg $\mathrm{Br}$ 2011;93(8):1126-30. CrossRef
25. Karapınar L, Öztürk H, Sürenkök F, Us MR. 15.000 yenidoğanın ortopedik yönden değerlendirilmesi. Artroplasti Artroskopik Cer 2001;12(2):139-43.

26. Ömeroğlu $\mathrm{H}$, Koparal $\mathrm{S}$. The role of clinical examination and risk factors in the diagnosis of developmental dysplasia of the hip: a prospective study in 188 referred young infants. Arch Orthop Trauma Surg 2001;121(1-2):7-11.

27. Oğuz T, Ege A, Güngör Ş, Toppare MT, Erdemtok N. 1099 bebeğin Graf yöntemi ile ultrasonografik değerlendirilmesi. Artroplasti Artroskopik Cer 1996;7:64-6.

28. Köse N, Ömeroğlu H, Özyurt B, Akçar N, Özçelik A, Inan U, Seber S. Our three-year experience with an ultrasonographic hip screening program conducted in infants at 3 to 4 weeks of age. Acta Orthop Traumatol Turc 2006;40(4):285-90.

29. Doğruel H, Atalar H, Yavuz OY, Uraş I, Günay C, Şaylı U. Türkiye'de Gelişimsel Kalça Displazisi Sıklığının ve Tarama Programlarının Değerlendirilmesi. Türkiye Klinikleri J Med Sci 2008;28(3):357-60.

30. Demirhan M, Şar C, Aydınok Ç, Çakmak M, Çoban A. Doğumsal kalça çıkığının tanısında ultrasonografi. Acta Orthop Traumatol Turc 1994;28:8-14.

31. TC Türkiye İstatistik Kurumu Başkanlı̆̆ı, http://www.tuik.gov.tr. 